\title{
The Energy Release in Great Earthquakes
}

\author{
Hiroo Kanamori \\ Seismological Laboratory. California Institute of Technology, Pasadena, California 91125
}

\begin{abstract}
The conventional magnitude scale $M$ suffers saturation when the rupture dimension of the earthquake exceeds the wavelength of the seismic waves used for the magnitude determination (usually $5-50 \mathrm{~km}$ ). This saturation leads to an inaccurate estimate of energy released in great earthquakes. To circumvent this problem the strain energy drop $W$ (difference in strain energy before and after an earthquake) in great earthquakes is estimated from the seismic moment $M_{0}$. If the stress drop $\Delta \sigma$ is complete, $W=W_{0}=$ $(\Delta \sigma / 2 \mu) M_{0} \sim M_{0} /\left(2 \times 10^{4}\right)$, where $\mu$ is the rigidity; if it is partial, $W_{0}$ gives the minimum estimate of the strain energy drop. Furthermore, if Orowan's condition, i.e., that frictional stress equal final stress, is met, $W_{0}$ represents the seismic wave energy. A new magnitude scale $M_{w}$ is defined in terms of $W_{0}$ through the standard energy-magnitude relation $\log W_{0}=1.5 M_{w}+11.8 . M_{w}$ is as large as 9.5 for the 1960 Chilean earthquake and connects smoothly to $M_{B}$ (surface wave magnitude) for earthquakes with a rupture dimension of about $100 \mathrm{~km}$ or less. The $M_{\omega}$ scale does not suffer saturation and is a more adequate magnitude scale for great earthquakes. The seismic energy release curve defined by $W_{0}$ is entirely different from that previously estimated from $M_{s}$. During the 15-year period from 1950 to 1965 the annual average of $W_{0}$ is more than 1 order of magnitude larger than that during the periods from 1920 to 1950 and from 1965 to 1976. The temporal variation of the amplitude of the Chandler wobble correlates very well with the variation of $W_{0}$, with a slight indication of the former preceding the latter. In contrast, the number $N$ of moderate to large earthquakes increased very sharply as the Chandler wobble amplitude increased but decreased very sharply during the period from 1945 to 1965 , when $W_{0}$ was largest. One possible explanation for these correlations is that the increase in the wobble amplitude triggers worldwide seismic activity and accelerates plate motion which eventually leads to great decoupling earthquakes. This decoupling causes the decline of moderate to large earthquake activity. Changes in the rotation rate of the earth may be an important element in this mechanism.
\end{abstract}

\section{INTRODUCTION}

The energy release in earthquakes is one of the most fundamental subjects in geophysics. In most cases the amount of energy $E$ released in seismic waves is estimated from the earthquake magnitude $M$ through the magnitude-energy relation $\log E=1.5 M+11.8$ developed by Gutenberg and Richter [Gutenberg, 1956a]. While this relation was very carefully calibrated through repeated revisions and is considered to give a reasonably accurate estimate of seismic wave energy for most earthquakes, the validity of this relation is questionable for great earthquakes. Here great earthquakes are those with a very large, $100 \mathrm{~km}$ or greater, rupture length. This arises from the fact that for such a great earthquake the magnitude $M$ which is determined at the period of $20 \mathrm{~s}$ (or converted from $m$ (body wave magnitude) determined at shorter periods) does not represent the entire rupture process of an earthquake. In fact, there is little correlation between $M$ and the rupture length for great earthquakes. Thus the energy $E$ estimated from $M$ is very uncertain for great earthquakes. Yet it is such great earthquakes that contribute most to the seismic energy budget. In order to circumvent this difficulty we estimate in this paper the energy involved in great earthquakes on the basis of static source parameters such as the seismic moment and the area of the fault plane. Since the absolute level of stress involved in faulting is unknown, it is not possible to determine the change in the strain energy before and after an earthquake. However, it is possible to estimate the minimum strain energy drop which, under reasonable conditions, approximates the seismic wave energy. Since the static source parameters are very accurately determined for many great earthquakes, this method gives accurate estimates of energy for great earthquakes, which have the greatest contribution to the seismic energy budget. It is hoped that this method provides a more

Copyright (C 1977 by the American Geophysical Unıon. meaningful basis for various studies pertaining to global processes such as heat flow, Chandler wobble, and plate motions.

\section{Compilation of SeISMic Moments of GREAT EARTHQUAKES}

The seismic moment $M_{0}$, which is defined by $\mu \overline{D S}$ ( $\mu$ is the rigidity; $\bar{D}$ is the average offset on the fault; and $S$ is the area of the fault), is one of the most accurately determined seismic source parameters. For many great earthquakes, $M_{0}$ has been determined by using long-period body waves, surface waves, free oscillations, and geodetic data. A partial list is found in the work by Kanamori and Anderson [1975b]. For earthquakes for which no direct determination of $M_{0}$ has been made, we estimate it from the area of the fault plane $S$ and/or the 100-s magnitude determined by Brune and Engen [1969].

- A remarkable linearity between $\log M_{0}$ and $\log S$ has been noted by $A k i$ [1972], Thatcher and Hanks [1973], Kanamori and

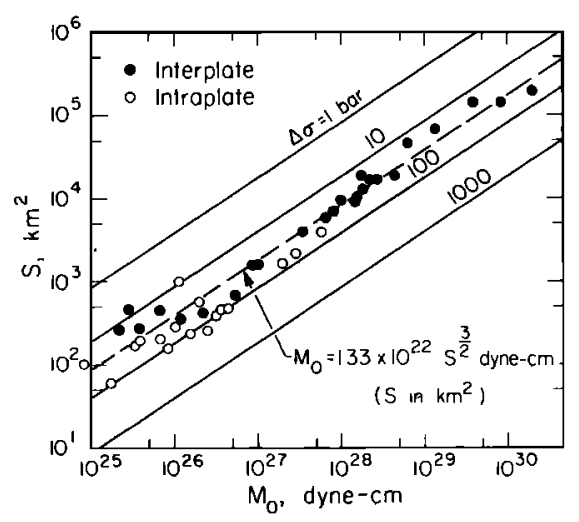

Fig. 1. The relation between the fault area and the seismic moment (modified from Kanamori and Anderson [1975b]). The dashed line gives the average $M_{0}$ versus $S$ relation suggested by $A b e$ [1975a]. 
TABLE 1. Great Earthquakes

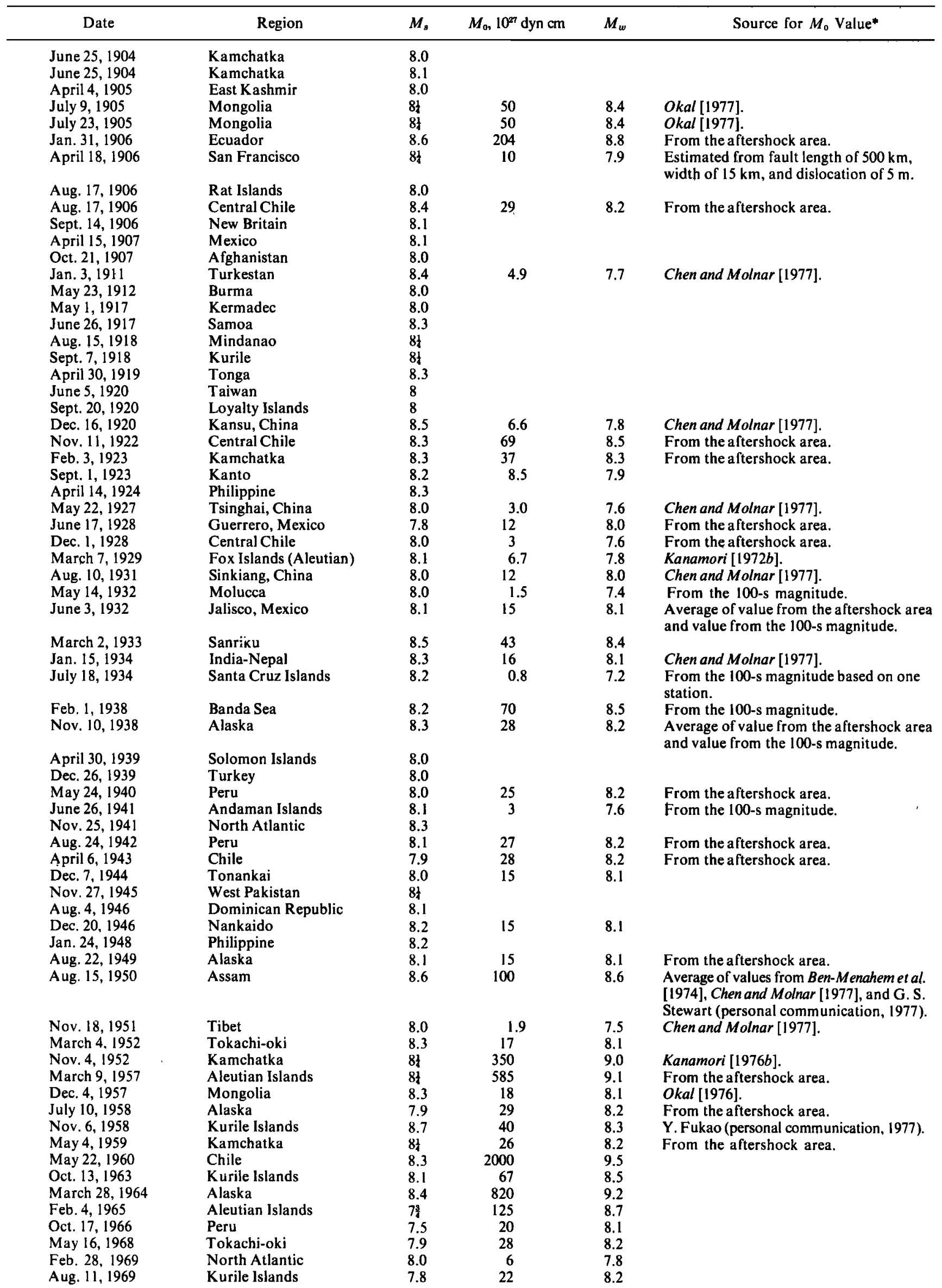


TABLE 1. (continued)

\begin{tabular}{|c|c|c|c|c|c|}
\hline Date & Region & $M_{\mathrm{a}}$ & $M_{0}, 10^{27}$ dyn cm & $M_{w}$ & Source for $M_{0}$ Value* \\
\hline $\begin{array}{l}\text { May } 31,1970 \\
\text { Jan. } 10,1971\end{array}$ & $\begin{array}{l}\text { Peru } \\
\text { West New Guinea }\end{array}$ & $\begin{array}{l}7.8 \\
8.1\end{array}$ & 10 & 7.9 & \\
\hline Oct. 3,1974 & Peru & 7.6 & 15 & 8.1 & $\begin{array}{l}\text { G.S. Stewart (personal communication, } \\
\text { 1977). }\end{array}$ \\
\hline $\begin{array}{l}\text { May } 26,1975 \\
\text { July } 27,1976\end{array}$ & $\begin{array}{l}\text { North Atlantic } \\
\text { China }\end{array}$ & $\begin{array}{l}7.9 \\
8.0\end{array}$ & $\begin{array}{l}5 \\
2\end{array}$ & $\begin{array}{l}7.7 \\
7.5\end{array}$ & $\begin{array}{l}\text { Hadley and Kanamori [1975]. } \\
\text { Revised from Stewart et al. [1976]. }\end{array}$ \\
\hline Aug. 16, 1976 & Mindanao & 8.2 & 19 & 8.1 & $\begin{array}{l}\text { G. S. Stewart (personal communication, } \\
\text { 1977). }\end{array}$ \\
\hline
\end{tabular}

The values of $M_{0}$ not referenced are taken from Table 1 of Kanamori and Anderson [1975b].

Anderson [1975b], Abe [1975a], and Geller [1976]. This linearity is interpreted in terms of constant average stress drop in earthquakes [Chinnery, 1964]. Figure 1 demonstrates this linearity for large and great earthquakes. Abe [1975a] and Geller and Kanamori [1977] suggest a relation

$$
M_{0}=1.23 \times 10^{22} S^{3 / 2} \text { dyn cm }
$$

where $S$ is in square kilometers, to represent the overall relation between $S$ and $M_{0}$. In many cases the aftershock area defined at a relatively early stage of the aftershock sequence, usually 1 day after the main shock, is used for $S$. This procedure involves some ambiguity but is adequate for the present purpose. Utsu and Seki [1954], Fedotov [1965], Mogi [1968a, b], Sykes [1971], Kelleher [1972], and Kelleher et al. [1973] mapped aftershock areas and rupture zones of many large and great earthquakes, including those for which no direct determination of $M_{0}$ has been made. We estimate $M_{0}$ of these earthquakes by using (1) and the size of the rupture zones determined by these authors. Although not very essential, one adjustment is made. The rupture zones determined by these authors are based on the aftershock area at a relatively later stage, usually several months, after the main shock, while $S$ used in (1) is determined from the aftershock area at a relatively early stage, usually 1 day. Comparison between these two sets of data suggests that the former is, on the average, $75 \%$ larger than the latter. Therefore in using (1) we divided the size of the published rupture zones by 1.75 . The results of moment determinations by this method are listed in Table 1.

Brune and Engen [1969] determined 100-s magnitude $M_{100}$ for 21 great earthquakes. Since $M_{100}$ is determined from the spectral amplitude of $100-\mathrm{s}$ mantle surface waves, it can be used to estimate $M_{0}$ if the corner period is shorter than $100 \mathrm{~s}$. In fact, there is a very good correlation between $M_{100}$ and $\log$ $M_{0}$. For 7 out of the 21 events of Brune and Engen [1969], direct determination of $M_{0}$ is available. Comparison of $M_{100}$ and $\log M_{0}$ for these events leads to a relation

$$
\log M_{0}=2.83 M_{100}+4.83
$$

where $M_{0}$ is in dyne centimeters. This relation is used to estimate $M_{0}$ for the remaining 14 events. The results are listed in Table 1 . Table 1 includes all shallow earthquakes of $M_{s} \geq$ 8.0 since 1904 (when the magnitude refers specifically to the 20-s surface wave magnitude, it is denoted by $M_{a}$ ). These earthquakes are taken from Gutenberg and Richter [1954] for the period from 1904 to 1952, from the Science Almanac [Tokyo Astronomical Observatory, 1975, 1977] for the period from 1953 to 1975 and from the Preliminary Determination of Epicenters (PDE) cards of the U.S. Geological Survey for
1976. Nine earthquakes of $M_{s}<8.0$ for which $M_{0}$ is known are included.

For the period from 1921 to 1976 the data are fairly complete; there are eight earthquakes for which $M_{0}$ is unknown, but only four of them have $M_{s}$ larger than 8.1. It is notable that in terms of $M_{0}$, four earthquakes, the 1960 Chilean, 1964 Alaskan, 1957 Aleutian Islands, and 1952 Kamchatka earthquakes, dominate. For the period prior to 1920 , Table 1 is very incomplete, except around 1905 and 1906.

\section{Moment $M_{0}$, Minimum Strain Energy Drop $W_{0}$, ANd a New Magnitude Scale $M_{w}$}

The seismic moment $M_{0}$ is a very important earthquake parameter that measures the overall deformation at the source. In particular, it has a very important bearing on global phenomena such as plate motion [Brune, 1968; Davies and Brune, 1971; Kanamori, 1977], polar motion, and rotation of the earth [Smylie and Mansinha, 1968; Dahlen, 1973; Anderson, 1974; Press and Briggs, 1975; O'Connell and Dziewonski, 1976].

The seismic moment can be also interpreted in terms of the strain energy released in earthquakes. In the framework of the elastic stress relaxation model of an earthquake [Knopoff, 1958] the difference in the elastic strain energy $W$ before and after an earthquake can be written as

$$
W=\bar{\sigma} \bar{D} S
$$

where $\vec{\sigma}$ is the average stress during faulting. If the stress drop is complete, the stress drop $\Delta \sigma$ is equal to $2 \bar{\sigma}$, and

$$
W=W_{0}=\frac{1}{2} \Delta \sigma \bar{D} S=(\Delta \sigma / 2 \mu) M_{0}
$$

Since $\Delta \sigma$ is nearly constant at $20-60$ bars $=2-6 \times 10^{7} \mathrm{dyn} / \mathrm{cm}^{2}$ for very large earthquakes (Figure 1 ) and $\mu=3-6 \times 10^{11}$ dyn $/ \mathrm{cm}^{2}$ under crust-upper mantle conditions, $(\Delta \sigma / \mu) \sim 10^{-4}$ and (4) becomes

$$
W_{0} \sim M_{0} /\left(2 \times 10^{4}\right)
$$

Thus one can estimate $W_{0}$ by dividing the seismic moment by 2 $\times 10^{4}$.

When the stress drop is partial, the situation becomes more complicated. We let $\sigma_{0}$ and $\sigma_{1}$ be the initial and final stresses, respectively. Then

$$
W=\bar{\sigma} \bar{D} S=(\Delta \sigma / 2) \bar{D} S+\sigma_{1} \bar{D} S=W_{0}+\sigma_{1} \bar{D} S
$$

Unless a substantial overshoot occurs, $\sigma_{1}$ is usually positive, so that $W_{0}$ gives the minimum-estimate of the strain energy drop. We can attach more significance to $W_{0}$ if we introduce a model proposed by Orowan [1960]. We let $\sigma_{f}$ be the frictional stress during faulting. Then

$$
W=H+E
$$


TABLE 2. Earthquakes of Large $M_{w}$

\begin{tabular}{|c|c|c|}
\hline Event & Year & $M_{w}$ \\
\hline Chile & 1960 & 9.5 \\
\hline Alaska & 1964 & 9.2 \\
\hline Aleutian & 1957 & 9.1 \\
\hline Kamchatka & 1952 & 9.0 \\
\hline Ecuador & 1906 & 8.8 \\
\hline Aleutian & 1965 & 8.7 \\
\hline Assam & 1950 & 8.6 \\
\hline Kurile Islands & 1963 & 8.5 \\
\hline Chile & 1922 & 8.5 \\
\hline Banda Sea & 1938 & 8.5 \\
\hline Mongolia & 1905 & 8.4 \\
\hline Mongolia & 1905 & 8.4 \\
\hline Sanriku & 1933 & 8.4 \\
\hline Kamchatka & 1923 & 8.3 \\
\hline Kurile Islands & 1958 & 8.3 \\
\hline Chile & 1906 & 8.2 \\
\hline Alaska & 1938 & 8.2 \\
\hline Kamchatka & 1959 & 8.2 \\
\hline Tokachi-oki & 1968 & 8.2 \\
\hline Peru & 1940 & 8.2 \\
\hline Peru & 1942 & 8.2 \\
\hline Alaska & 1958 & 8.2 \\
\hline Chile & 1943 & 8.2 \\
\hline Kurile & 1969 & 8,2 \\
\hline Mexico & 1932 & 8.1 \\
\hline Tonankai & 1944 & 8.1 \\
\hline Nankaido & 1946 & 8.1 \\
\hline Alaska & 1949 & 8.1 \\
\hline Tokachi-oki & 1952 & 8.1 \\
\hline Mongolia & 1957 & 8.1 \\
\hline Peru & 1966 & 8.1 \\
\hline India-Nepal & 1934 & 8.1 \\
\hline Peru & 1974 & 8.1 \\
\hline Mindanao & 1976 & 8.1 \\
\hline Mexico & 1928 & 8.0 \\
\hline China & 1931 & 8.0 \\
\hline San Francisco & 1906 & 7.9 \\
\hline Kanto & 1923 & 7.9 \\
\hline Peru & 1970 & 7.9 \\
\hline
\end{tabular}

where $H=\sigma_{f} \overline{D S}$ is the frictional loss and $E$ is the wave energy. Using (3), we have

$$
\begin{aligned}
E=\bar{\sigma} \bar{D} S-\sigma_{f} \bar{D} S=(\Delta \sigma / 2) \bar{D} S+ & \bar{D} S\left(\sigma_{1}-\sigma_{f}\right) \\
& =W_{0}+\bar{D} S\left(\sigma_{1}-\sigma_{f}\right)
\end{aligned}
$$

Thus if Orowan's [1960] condition $\sigma_{1}=\sigma_{f}$ is met, $W_{0}$ is not only the minimum estimate of $W$ but also is equal to the wave energy [see also Savage and Wood, 1971].

Whether the earthquake stress drop is complete or partial is presently unresolved. Brune et al. [1969] argued, on the basis of lack of heat flow anomaly along the San Andreas fault, that frictional stress is very small. In this case the stress drop is nearly complete, and $W_{0}$ represents the actual strain energy drop. On the other hand, evidence for a very high ( $\sim 1 \mathrm{kbar})$ tectonic stress has been suggested primarily from the analysis of the deformation of the oceanic lithosphere [Hanks, 1971; Watts and Talwani, 1974; Caldwell et al., 1976]. If this high stress is representative of the tectonic stress that causes earthquakes, then the stress drop may be partial. Although this problem remains unresolved, $W_{0}$ is still a useful parameter in that it gives the minimum strain energy drop in earthquakes.

Furthermore, results of Trifunac [1972], Kanamori [1972a], Abe [1975b], Kanamori and Anderson [1975b], and Geller [1976] suggest that the stress drop is approximately equal to the effective stress; i.e., Orowan's [1960] condition $\sigma_{1}=\sigma_{f}$ is satisfied. Then (6) means that $W_{0}$ determined by $\left(4^{\prime}\right)$ is equal to the wave energy $E$.

For a more conventional measure of the 'size' of great earthquakes it is convenient to use a magnitude scale. To this end, we define a new magnitude scale for great earthquakes in terms of $W_{0}$ by using the Gutenberg-Richter magnitude-energy relation, $\log E=1.5 M+11.8$. We use $W_{0}$ calculated from $M_{0}$ for $E$ in this equation, calculate $M$, and denote it by $M_{w}$. The results are listed in Table 1 . Table 2 lists the 39 largest earthquakes on this scale. The 1960 Chilean earthquake has the largest $M_{w}, 9.5$. The 1964 Alaskan $\left(M_{w}=9.2\right), 1957$ Aleutian Islands $\left(M_{w}=9.1\right)$, and 1952 Kamchatka $\left(M_{w}=9.0\right)$ earthquakes follow. It is interesting to note that $M_{w}$ agrees very well with $M_{s}$ for many earthquakes with a rupture length of about $100 \mathrm{~km}$ (e.g., 1944 Tonankai, 1946 Nankaido, 1952 Tokachi-oki, 1966 Peru, 1923 Kanto, and 1970 Peru). This agreement may suggest that the Gutenberg-Richter magnitude-energy relation, $\log E=1.5 M+11.8$, gives the correct value of seismic wave energy for earthquakes up to this size, i.e., a rupture dimension of $\$ 100 \mathrm{~km}$. Thus the $M_{w}$ scale can be used as a natural continuation of the $M_{s}$ scale for great earthquakes. The saturation of the $M_{s}$ scale for great earthquakes [Kanamori and Anderson, 1975b; Geller, 1976; Chinnery and North, 1975] has been an inconvenient and sometimes a confusing element in the conventional magnitude scale. The use of $M_{w}$ eliminates this saturation.

\section{Temporal Variation of EnERgy Release IN EARTHQUAKES}

As shown in the previous section, $W_{0}=(\Delta \sigma / 2 \mu) M_{0}$ represents the minimum strain energy drop in an earthquake, and under the condition $\sigma_{1}=\sigma_{f}$ (i.e., Orowan's [1960] condition, or the condition that effective stress equal stress drop) it is equal to the seismic wave energy. The condition $\sigma_{1} \sim \sigma_{f}$ has been verified experimentally for several earthquakes.

Figure 2 shows $W_{0}$ for great earthquakes as a function of year plotted from Table 1 . The solid curve shows the annual average of $W_{0}$ obtained by taking a 5-year running average (taken at the center of the interval) of the data in Table 1. In the computation of the annual release curve, earthquakes for which the seismic moment $M_{0}$ is not known are inevitably

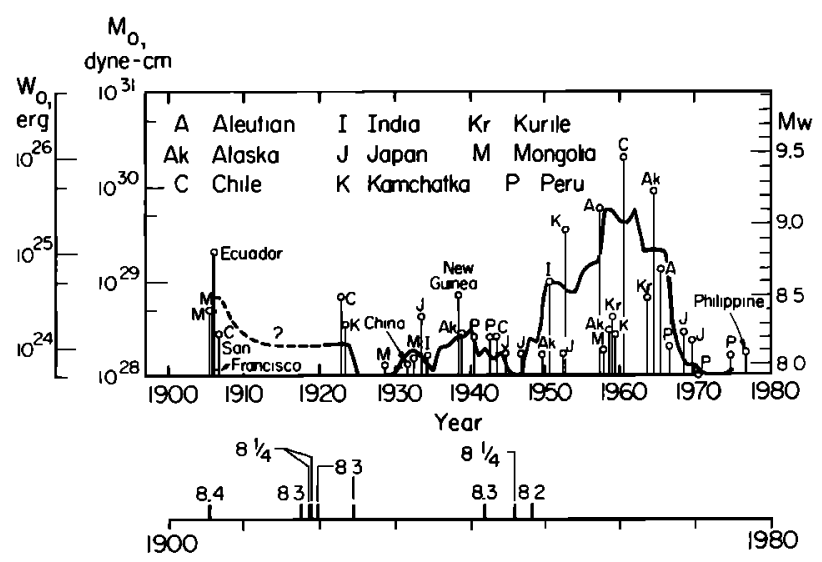

Fig. 2. The minimum strain energy drop $W_{0}$ (equal to the seismic wave energy if Orowan's [1960] condition is met) in great earthquakes as a function of year. The solid curve shows unlagged 5-year running average (in ergs per year) taken at the center of the interval. The ordinate is given in three scales, the seismic moment $M_{0}, W_{0}$, and $M_{w}$. Large earthquakes for which $M_{0}$ has not been determined are plotted at the bottom with the surface wave magnitude $M_{s}$. 


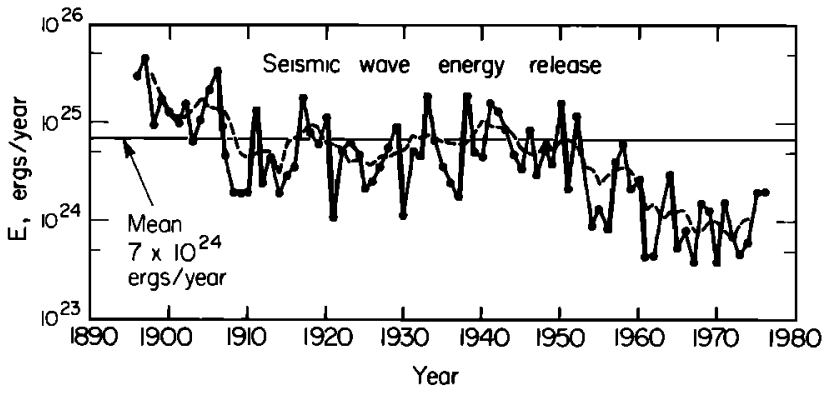

Fig. 3. Seismic wave energy released in earthquakes computed from the surface wave magnitude $M_{s}$ through the Gutenberg-Richter energy versus magnitude relation. The dashed curve shows the unlagged 5year running average.

ignored. However, since 1921 , only four events of $M_{s} \geq 8.2$ are missing, and it is unlikely that the omission of these events affects the energy release curve drastically. For the period prior to 1920, Table 1 is very incomplete except around 1906. The annual average of $W_{0}$ for the period from 1920 to 1976 is $4.5 \times 20^{24} \mathrm{ergs} / \mathrm{yr}$.

It is remarkable that during the 15 -year period from 1950 to 1965 the annual average of $W_{0}$ is more than an order of magnitude larger than that during the periods from 1920 to 1950 and from 1965 to 1976 . Another peak is suggested around the turn of the century, but its confirmation must await further studies.

As mentioned earlier, $W_{0}$ represents the minimum strain energy drop, and the actual strain energy drop can be larger than this, if the stress drop in great earthquakes is only partial. Even then, if the fractional stress drop is about the same for all earthquakes, Figure 2 still gives the correct trend of the relative strain energy release.

\section{Correlation Between $\boldsymbol{W}_{\mathbf{0}}$, Gutenberg-Richter ENERGY, NUMBER OF EVENTS, AND Polar Motion of the Earth}

It is instructive to compare the temporal variation of $W_{0}$ with the conventional energy release curve computed from the magnitude. Gutenberg [1956b] calculated the annual energy release for the period from 1896 to 1955 by using the earthquake magnitude and the energy versus magnitude relation log $E=1.5 M+11.8$. We extended this calculation to 1975 by using the catalog of earthquakes listed in the Science Almanac [Tokyo Astronomical Observatory, 1975, 1977] and to 1976 by using the PDE cards of the U.S. Geological Survey and Caltech determinations. The energy $E$ calculated by this method, here called the Gutenberg-Richter energy, refers to the seismic

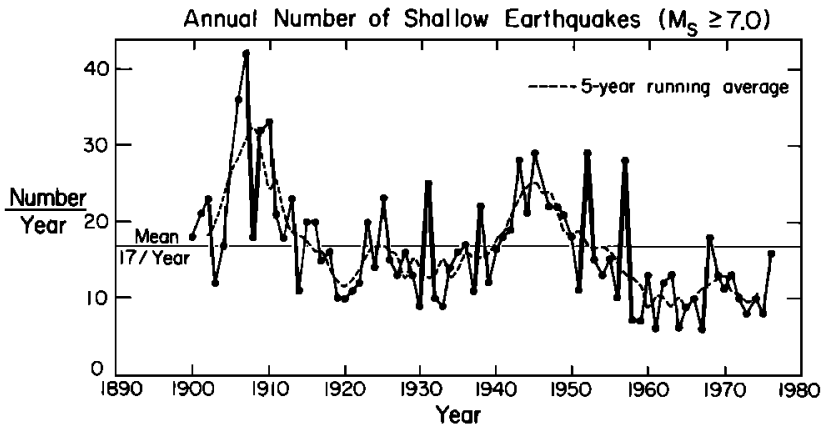

Fig. 4. The annual number of earthquakes of $M_{s} \geq 7.0$. The dashed curve shows the unlagged 5 -year running average. wave energy radiated by earthquakes. As was discussed earlier, however, because of the saturation of the ordinary magnitude scale this relation tends to underestimate the wave energy of great earthquakes. Thus the annual energy curve computed by this method can be considered to approximate the wave energy radiated by earthquakes of up to moderate to large size. Figure 3 shows the variation of $E$ as a function of year.

Another measure of seismic activity is the number of earthquakes. Figure 4 shows the annual number $N$ of earthquakes of $M_{s} \geq 7.0$ taken from the catalog of the Science Almanac [Tokyo Astronomical Observatory, 1975, 1977]. Since $96.7 \%$ of these earthquakes have $M_{s}$ between 7 and 8 , the temporal variation of $N$ is more representative of the activity of moderate to large earthquakes.

Since the estimate of the Gutenberg-Richter energy $E$ based on the magnitude-energy relation can be greatly affected by errors in the magnitude of the few larger earthquakes, the number of events $N$ is more representative of the global activity of moderate to large earthquakes than $E$.

Despite the large uncertainty in $E$ (Figure 3 ) the general trends of the curves of $E$ and $N$ are very similar to each other. In particular, both $E$ and $N$ show a very steady decrease since the middle 1940 's. It is quite remarkable that during this period there was a very pronounced increase in $W_{0}$. The correlation is shown in Figure 5. Although the energy release curve itself may be subject to considerable uncertainty, it is certain that the number of earthquakes of $M_{B} \geq 7.0$ decreased very sharply during the period when many great earthquakes with a very large rupture dimension $(500-1000 \mathrm{~km}$ ) occurred from 1952 to 1965. This complementary occurrence of great earthquakes and moderate to large earthquakes is a very intriguing feature, suggestive of a causal relationship between these two groups of earthquakes.

In Figure 5 is also plotted the temporal variation of the amplitude (envelope) of the Chandler wobble taken from $A n$ derson [1974] (for the period from 1900 to 1960) and $O^{\prime}$ Connell and Dziewonski [1976] (for the period from 1960 to 1970). The variation of the wobble shows a trend very similar to that of $W_{0}$ for the period from 1920 to 1970 . A peak in the wobble curve around 1910 may be correlatable to a peak in $W_{0}$ suggested around the turn of the century. Although the data presented in this paper are not complete for this period, it is notable that many large earthquakes occurred all over the world around the turn of the century, e.g., Alaska, Tibet, the

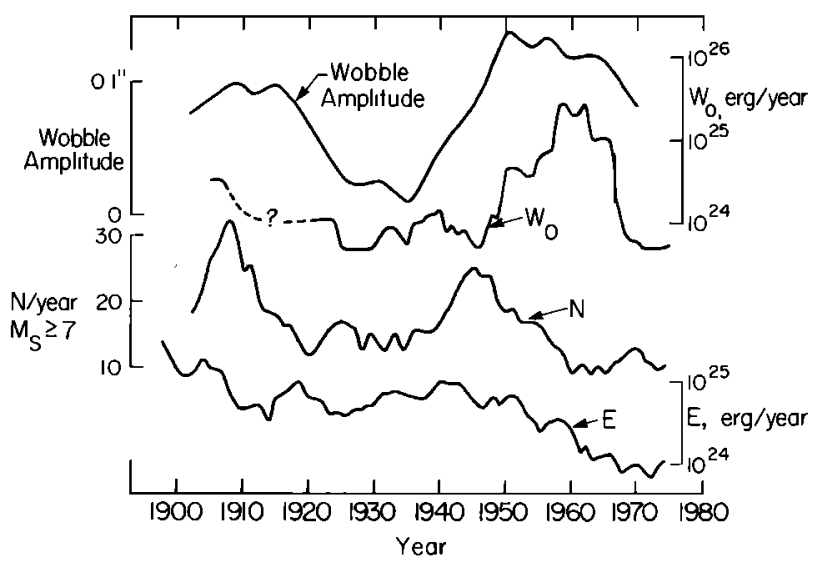

Fig. 5. Correlation between the amplitude (envelope) of the Chandler wobble, $W_{0}$ (5-year running average), annual number $N$ of earthquakes of $M_{s} \geq 7.0$ (5-year running average), and the GutenbergRichter energy $E$ (5-year running average). 


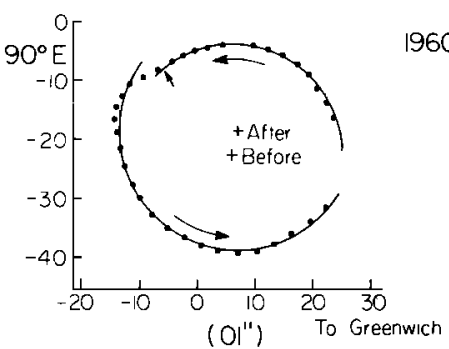

Chilean earthquake

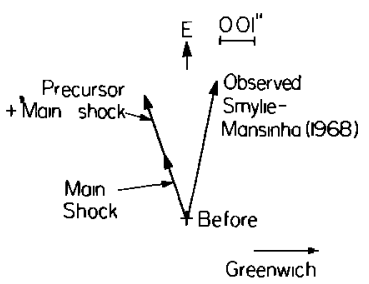

Fig. 6. The polar motion before and after the 1960 Chilean earthquake (left) inferred by Smylie and Mansinha [1968]. The center of the polar motion before and after the earthquake is shown by a plus sign. Comparison of the observed and computed polar shift is shown on the right. The computation is made by using Dahlen's [1973] expression for the source parameters determined by Kanamori and Cipar [1974].

Philippines, Mexico, New Zealand, Santa Cruz Island, Russia, the Caribbean, Loyalty Island, Guatemala, and Java.

\section{Discussion AND CONCLUSION}

As shown in the previous section, $W_{0}$ represents the energy release in great earthquakes, while $E$ or $N$ represents that in moderate to large earthquakes. Therefore if there is a causal relation between the wobble and earthquake activity at all, it is more reasonable to compare the wobble with $W_{0}$ than with $N$ or $E$.

Anderson [1974] discussed several possible mechanisms that would explain such a correlation. The first possibility is that the deformation caused by a great earthquake excites the Chandler wobble. The second is that a change in the polar motion caused by other factors, such as atmospheric changes, affects the plate motion, thereby triggering great earthquakes and other major earthquakes. Combination of these two mechanisms is also possible. Regarding the first possibility, many investigations have been made, those by Smylie and Mansinha [1968], Dahlen [1973], Israel et al. [1973], Press and Briggs [1975], and O'Connell and Dziewonski [1976] to mention a few. One problem is that the deformation caused by even a great earthquake is not large enough to excite the Chandler wobble unless a large aseismic slip is assumed [Dahlen, 1973; $O^{\prime}$ Connell and Dziewonski, 1976; Kanamori, 1976a]. Only the 1960 Chilean earthquake, the largest of all in $M_{w}$, can account for the shift of the pole position when the preseismic anelastic deformation reported by Kanamori and Cipar [1974] and Kanamori and Anderson [1975a] is included (Figure 6). Existence of large aseismic deformation has been suggested for very large tsunami earthquakes such as the 1896 Sanriku earthquake and the 1946 Aleutian Islands earthquake [Kanamori, [1972b], for the 1906 San Francisco earthquake [Thatcher, 1974], for the 1952 Kamchatka earthquake [Kanamori, 1976b], and for a Japanese earthquake [Fukao and Furumoto, 1975]. Also, disparity between seismic slıp and plate motion provides evidence for such aseismic deformation [Kanamori, 1977]. Thus the first possibility still remains valid.

The second possibility is very intriguing. Recent analysis of Wilson [1975] suggests that atmospheric motions can maintain the Chandler wobble. In this context, Anderson [1975] notes that the temporal variation of global temperatures, one climatic indicator, is very similar to that of the wobble. It is quite possible that the increase in the amplitude of the Chandler wobble caused by such effects accelerates global plate motions, thereby triggering great earthquakes at plate boundaries. Figure 5 indicates that the sharp increase in $W_{0}$ around 1960 began very shortly after the amplitude of the wobble became maximum in 1950. This coincidence may be suggestive of the second possibility. It is remarkable that the annual number of earthquakes $N$ increased toward 1945 and then decreased very sharply since then. One possibility is that when the wobble amplitude increases, the world seismic activity increases, and plate motion may be accelerated. However, once major plate boundaries are decoupled in great earthquakes, moderate to large earthquake activity declines owing to decrease in intraplate and interplate stresses as a result of plate decoupling.

It is equally possible that changes in the rotation rate of the earth are responsible for accelerated plate motions which in turn cause the variation in the Chandler wobble and great earthquakes. The change in the rotation rate of the earth correlates very well with the Chandler wobble [Anderson, 1974]. Since the rotational energy of the earth is so much greater than the energy involved in plate motions and earthquakes, even a small perturbation in the rotation can have a significant effect on earthquakes and plate motion.

The conclusions are as follows: (1) The minimum estimate of the strain energy drop in earthquakes, $W_{0}$, which can be estimated from the seismic moment $M_{0}$ can be considered to represent, under Orowan's [1960] condition, the seismic wave energy release. (2) Since $W_{0}$ can be estimated accurately for great earthquakes, it provides a more accurate picture of the seismic energy budget. (3) A new magnitude scale $M_{w}$ is defined in terms of $W_{0}$. It is as large as 9.5 for the 1960 Chilean earthquake and connects smoothly to $M_{s}$ for moderate to large earthquakes. Therefore $M_{\omega}$ provides a convenient magnitude scale which does not saturate. (4) The temporal variation of $W_{0}$, the energy release in great earthquakes, is very different from that in moderate to large earthquakes. The activity of moderate to large earthquakes was very low when $W_{0}$ was largest during the period from 1950 to 1965 . (5) The amplitude of the Chandler wobble seems to correlate very well with $W_{0}$, with a slight indication of the former preceding the latter. (6) One possible mechanism that accounts for the correlation between the wobble, $W_{0}$, and the activity of moderate to large earthquakes is that an increase in wobble amplitude triggers worldwide seismic activity and accelerates plate motion, which eventually leads to great decoupling earthquakes. This decoupling causes the decline of moderate to large earthquake activity.

Acknowledgments. I have benefited greatly from stimulating discussions with and helpful comments by Don Anderson, Bob Geller and Yoshio Fukao. The idea of using static parameters to estimate the minimum energy involved in great earthquakes emerged from conversatıons held with Don Anderson and Tom Hanks. Yoshio Fukao and Gordon Stewart kındly made avallable some of their results prior to publication. This research was supported by the Earth Sciences Section of the National Science Foundation, grants EAR76-14262 and EAR 74-22489. Contribution 2867 of the Division of Geological and Planetary Sciences, California Institute of Technology, Pasadena, California 91125 .

\section{REFERENCES}

Abe, K., Reliable estimation of the seismic moment of large earthquakes, J. Phys. Earth, 23, 381-390, $1975 a$.

Abe, K., Static and dynamic fault parameters of the Saitama earthquake of July 1, 1968, Tectonophysics, 27, 223-238, $1975 b$.

Aki, K., Earthquake mechanism, Tectonophysics, 13, 423-446, 1972.

Anderson, D. L., Earthquakes and the rotation of the earth, Science, 186, 49-50, 1974.

Anderson, D. L., Frontiers of geophysics: Earthquakes, volcanos, climate, and the rotation of the earth (abstract), Eos Trans. $A G U$, $56,346,1975$.

Ben-Menahem, A., E. Aboodi, and R. Schild, The source of the great 
Assam earthquake-An interplate wedge motion, Phys. Earth Planet. Interiors, 9, 265-289, 1974.

Brune, J., Seismic moment, seismicity, and rate of slip along major fault zones, J. Geophys. Res., 73, 777-784, 1968.

Brune, J. N., and G. R. Engen, Excitation of mantle Love waves and definition of mantle wave magnitude, Bull. Seismol. Soc. Amer., 59, 923-933, 1969.

Brune, J. N., T. L. Henyey, and R. F. Roy, Heat flow, stress, and the rate of slip along the San Andreas fault, California, J. Geophys. Res., 74, 3821-3827, 1969.

Caldwell, J. G., W. F. Haxby, D. E. Karig, and D. L. Turcotte, On the applicability of a universal elastic trench profile, Earth Planet. Sci. Lett., 3I, 239-246, 1976.

Chen, W. P., and P. Molnar, Seismic moments of major earthquakes and the average rate of slip in central Asia (abstract), Eos Trans. $A G U, 58,182,1977$.

Chinnery, M. A., The strength of the earth's crust under horizontal shear stress, J. Geophys. Res., 69, 2085-2089, 1964.

Chinnery, M. A., and R. G. North, The frequency of very large earthquakes, Science, 190, 1197-1198, 1975.

Dahlen, F. A., A correction to the excitation of the Chandler wobble by earthquakes, Geophys. J. Roy. Astron. Soc., 32, 203-217, 1973.

Davies, G. F., and J. N. Brune, Regional and global fault slip rates from seismicity, Nature, 229, 101-107, 1971.

Fedotov, S. A., Regularities of the distribution of strong earthquakes in $\mathrm{K}$ amchatka, the Kuril lslands and northeastern Japan (in Russian), Izv. Akad. Nauk SSSR Fiz. Zemli, 36(203), 66-93, 1965.

Fukao, Y., and M. Furumoto, Mechanism of large earthquakes along the eastern margin of the Japan sea, Tectonophysics, 24, 247-266, 1975.

Geller, R. J., Scaling relations for earthquake source parameters and magnitudes, Bull. Seismol. Soc. Amer. 66, 1501-1523, 1976.

Geller, R. J., and H. Kanamori, Magnitude of great shallow earthquakes from 1904 to 1952, Bull. Seismol. Soc. Amer., 67, in press, 1977.

Gutenberg, B., The energy of earthquakes, Quart. J. Geol. Soc. London, 112, 1-14, 1956a.

Gutenberg, B., Great earthquakes 1896-1903, Eos Trans. AGU, 37, $608-614,1956 b$.

Gutenberg, B., and C. F. Richter, Seismicity of the Earth, 2nd ed., 310 pp., Princeton University Press, Princeton, N. J., 1954.

Hadley, D. M., and H. Kanamori, Seismotectonics of the eastern Azores-Gibraltar Ridge (abstract), Eos Trans. AGU, 56, 1028, 1975.

Hanks, T. C., The Kuril trench-Hokkaido rise system: Large shallow earthquakes and simple models of deformation, Geophys. J., 23 , 173-189, 1971 .

Israel, M., A. Ben-Menahem, and S. J. Singh, Residual deformation of real earth models with application to the Chandler wobble, Geophys. J. Roy. Astron. Soc., 32, 219-247, 1973.

Kanamori, H., Determination of effective tectonic stress associated with earthquake faulting-Tottori earthquake of 1943, Phys. Earth Planet. Interiors, 5, 426-434, 1972a.

Kanamori, H., Mechanism of Tsunami earthquakes, Phys. Earth Planet. Interiors, 6, 346-359, $1972 b$.

Kanamori, H., Are earthquakes a major cause of the Chandler wobble?, Nature, 262, 254-255, 1976a.

Kanamori, H., Re-examination of the earth's free oscillations excited by the Kamchatka earthquake of November 4, 1952, Phys. Earth Planet. Interiors, 11, 216-226, 1976b.

Kanamori, H., Seismic and aseismic slip along subduction zones and their tectonic implications, in Island Arcs, Deep Sea Trenches, and Back-Arc Basins, Maurice Ewing Ser., vol. I, edited by M. Talwani and W. C. Pitman III, AGU, Washington, D. C., in press, 1977.

Kanamori, H., and D. L. Anderson, Amplitude of the earth's free oscellations and long-period characteristics of the earthquake source, J. Geophys. Res., 80, 1075-1078, 1975a.
Kanamori, H., and D. L. Anderson, Theoretical basis of some empirical relations in seismology, Bull. Seismol. Soc. Amer., 65, 1073-1095, 1975b.

Kanamori, H., and J. J. Cipar, Focal process of the great Chilean earthquake, May 22, 1960, Phys. Earth Planet. Interiors, 9, 128-136, 1974

Kelleher, J. A., Rupture zones of large South American earthquakes and some predictions, J. Geophys. Res., 77, 2087-2103, 1972.

Kelleher, J., L. Sykes, and J. Oliver, Possible criteria for predicting earthquake locations and their application to major plate boundaries of the Pacific and the Caribbean, J. Geophys. Res., 78, 2547-2585, 1973 .

Knopoff, L., Energy release in earthquakes, Geophys. J., I, 44-52, 1958.

Mogi, K., Development of aftershock areas of great earthquakes, Bull. Earthquake Res. Inst. Tokyo Univ., 46, 175-203, 1968a.

Mogi, K., Some features of recent seismic activity in and near Japan, 1, Bull. Earthquake Res. Inst. Tokyo Univ., 46, 1225-1236, 1968 b.

O'Connell, R. J., and A. M. Dziewonski, Excitation of the Chandler wobble by large earthquakes, Nature, 262, 259-262, 1976

Okal, E. A., A surface-wave investigation of the rupture mechanism of the Gobi-Altai (December 4, 1957) earthquake, Phys. Earth Planet. Interiors, 12, 319-328, 1976.

Okal, E. A., The July 9 and 23, 1905 Mongolian earthquakes: A surface-wave investigation, Earth Planet. Sci. Lett, 34, 326-331, 1977.

Orowan, E., Mechanism of seismic faulting, Geol. Soc. Amer. Mem., $79,323-345,1960$.

Press, F., and P. Briggs, Chandler wobble, earthquakes, rotation, and geomagnetic changes, Nature, 256, 270-273, 1975.

Savage, J. C., and M. D. Wood, The relation between apparent stress and stress drop, Bull. Seismol. Soc. Amer., 6I, 1381-1388, 1971.

Smylie, D. E., and L. Mansinha, Earthquakes and the observed motion of the rotation pole, J. Geophys. Res., 73, 7661-7663, 1968.

Stewart, G. S., R. Butler, and H. Kanamori, Surface and body wave analysis for the February 4, 1975, Haicheng and July 27, 1976, Tangshan Chinese earthquakes (abstract), Eos Trans. AGU, 57,953, 1976.

Sykes, L. R., Aftershock zones of great earthquakes, seismicity gaps, and earthquake prediction for Alaska and the Aleutians, $J$. Geophys. Res., 76, 8021-8041, 1971.

Thatcher, W., Strain release mechanism of the 1906 San Francisco earthquake, Science, 184, 1283-1285, 1974.

Thatcher, W., and T. Hanks, Source parameters of southern California earthquakes, J. Geophys. Res., 78, 8547-8576, 1973.

Tokyo Astronomical Observatory, Science Almanac, Maruzen, Tokyo, 1975.

Tokyo Astronomical Observatory, Science Almanac, Maruzen, Tokyo, 1977.

Trifunac, M. D., Stress estimates for the San Fernando, California, earthquake of February 9, 1971; Main event and thirteen aftershocks, Bull. Seismol. Soc. Amer., 62, 721-750, 1972.

Utsu, T., and A. Seki, A relation between the area of aftershock region and the energy of main shock (in Japanese), J. Seismol. Soc. Jap., 7 , 233-240, 1954.

Watts, A. B., and M. Talwani, Gravity anomalies seaward of deep-sea trenches and their tectonic implications, Geophys. J., 36, 57-90, 1974.

Wilson, C. R., Meteorological excitation of the earth's wobble, Ph.D. thesis, Univ. of Calif., San Diego, 1975.

(Received January 31, 1977;

revised March 21, 1977;

accepted March 22, 1977.) 